9 Holt S. Paediatric anaesthesia. Br.Med f 1985;291:673.

10 Fisher NGS, Armitage EN, Williams PAP. Paediatric anaesthesia. Br Med f $1985 ; 291: 673$

11 Carter AJ. Paediatric anaesthesia. Br. Med 7 1985;291:824.

12 Lask B. Paediatric anaesthesia. Br Med f 1985:291:824.

13 While A Paediatric anaesthesia. Br Med 7 1985;291:824.

14 Anonymous. Parents in the anaesthetic room [Editorial]. Lancet 1986;ii:903.

15 Davenport HT, Valman B. Parents in the anaesthetic room. Lance 1987;i:45-6.

16 Carter AJ Premedication for children Anaesthesia 1986;41:440.

17 Booker PD, Chapman DH. Premedication in children undergoing day care surgerv. Br f Anaesth 1979;51:1083-7.

18 Keneally JP. Day stay surgery in paediatrics. Clinics in Anaesthesiolog 1985;3:679-95

9 Thompson EJ, ed. Social trends 10. London: HMSO, 1980:290-1.

20 Hannallah RS, Rosales JK. Experience with parents' presence during anaesthesia induction in children. Canadian Anaesthetists Society fournal 1983;30:286-9
21 Schulman JL, Foley JM, Vernon DTA, Allan D. A study of the effect of the mother's presence during anesthesia induction. Pediatrics 1967;39:111-4. Jago RH. Induction of anaesthesia in children. Anaesthesia 1986:41:885.

23 Steward DJ. Anaesthesia for paediatric outpatients. Canadiun Anaesthetists Society Journal 1980;27:4126.

4 Johnson GG. Day case surgery for infants and children. Canadian Anaesthetists Society foumal 1983;30:553-7.

25 Jones SEF, Smith BAC. Anesthesia for pediatric day-surgery. F Pediatr Surg 1980;15:31-3.

26 Padfield NL, Twonig MMcD, Frazer ACL. Temazepam and trimeprazine compared with placebo as premedication in children. $\mathrm{Br} f$ Anaesth $1986 ; 58: 487-93$

27 Johnston CL, Bevan JL, Haig MJ, Kirnon V, Tousignant G. Parental presence during anesthesia induction. AORN $\mathcal{F}$ 1988;47:186-94.

28 Cohen D, Keneally J, Black A, Gaffrey S, Johnson A. Experience with day surgery. F Pediatr Surg 1980;15:21-5.

(Accepted 4 October 1989)

\title{
Effect of a training programme to reduce stress in carers of patients with dementia
}

\author{
H Brodaty, Meredith Gresham
}

\section{Abstract}

Objective-To reduce the psychological stress and improve the skills in coping of people who care for relatives with dementia.

Design-Assessment and suitability of carers by questionnaire; assessment of patients and carers in a hospital outpatient clinic; allocation to groups according to date of application to study. Linkage of groups of four carers and programme coordinator by telephone conference calls over 12 months after programmes. Reassessment at three, six, 12, and, for those in the "wait list" group, 18 months.

Setting-The programmes were conducted in the psychiatry unit of a Sydney teaching hospital.

Subjects-Eligible patients were less than 80 years old, had mild to moderate dementia, and lived at home with their carer. Of the 96 patient-carer pairs in the study, 33 were in the dementia carers' programme group, 31 were in the memory retraining group, and 32 were in the wait list group.

Interventions-Carers in the dementia carers' programme received training in coping with the difficulties of looking after patients with dementia while the patients had sessions in subjects such as memory retraining. In the memory retraining programme patients were admitted and received the patient component of the carers' programme while their carers had 10 days' respite. In the wait list group carers waited six months before undertaking the carers' programme.

Main outcome measures-Effect of the programmes on carers' general health questionnaire scores and the rate of placement of patients in institutions.

Results-At 12 months' follow up the carers' programme had resulted in significantly lower psychological stress among carers than the memory retraining programme (mean (SD) general health questionnaire scores at 0 months were $6.31(6.23)$ and $3.60(6.25)$ respectively, and at 12 months were $4.69(5.58)$ and $7.40(9.39) ; p<0.05$.) In the wait list group distress scores remained stable, even after the carers and patients had undertaken the carers' programme. Patients deteriorated over 12 months regardless of group allocation, but at $\mathbf{3 0}$ months, allowing for patients who died and could not be included in the analysis, $65 \%$ of patients in the carers' programme group were still living at home compared with $26 \%$ in the memory retraining programme group.

Conclusion-The intensive intervention pro- gramme described for carers of patients with dementia can reduce the psychological morbidity of the carer and delay the placement of the patient in an institution without increasing the use of health services by either patient or carer.

\section{Introduction}

Dementia is an unremitting burden' that leads to the carers of people with the condition becoming demoralised,,$^{2}$ isolated, ${ }^{3}$ and psychologically distressed..$^{3-6}$ Interventions to ease the plight of carers are needed, but empirical studies of such interventions have been sparse.

Intervention techniques have included attempts to enhance carers' skills in coping by cognitive behavioural approaches, training in problem solving, and educational therapy $^{6.9}$; meditative relaxation ${ }^{679}$; training in social skills ${ }^{5610}$; supportive counselling of individuals and groups or families, or both ${ }^{810}$; and management of stress. "The following outcomes were reported: reduced family burden ${ }^{810}$; decreased psychological morbidity ${ }^{10}$; increase in carers' knowledge about dementia $^{10}$; and increased assertiveness and tolerance. ${ }^{9}$ But these studies have various limitations: they comprised small numbers of subjects ${ }^{679}$; there was no follow up $^{6-810}$; interventions were limited ${ }^{(6-1)}$; there was a "floor effect" of low psychological morbidity of carers before training"; and the outcome of patients was not evaluated. ${ }^{6-11}$

We sought to overcome these methodological difficulties by designing an intervention programme for carers living at home with a relative with dementia. Our aim was to reduce distress and improve the quality of life for both patients and carers and to reduce the rate of placement of patients in institutions. In designing a package of appropriate interventions we took into account factors known to influence .carers' psychological distress. ${ }^{3}$ We reasoned that if we could modify these factors we would enhance our ability to reduce carers' psychological morbidity. We designed the dementia carers' programme, a highly structured 10 day residential training programme for patients and carers but aimed principally at carers and evaluated it against two control interventions.

Subjects and methods

SUBJECTS

Subjects were recruited by referral or publicity. Of the 96 carers, 40 indicated that they had entered the 
study on their own initiative, 16 were referred by local doctors, 15 entered the study through the Alzheimer's Disease and Related Disorders Society, eight after media publicity, and 17 through other sources.

Eligible patients were less than 80 years old (for follow up purposes) and had mild to moderate dementia, defined as Diagnostic and Statistical Manual type III dementia. They lived in a private home with a supporter, could understand English, did not wander, and were not aggressive. Mild to moderate dementia was defined as an activity of daily living score of zero or one. " Subjects were told that there were two treatment programmes but that if they wished to participate in the trial they would have to agree to accept whichever one they were allocated to. They were also told that neither programme offered a cure but that both offered the possibility of improvement in function.

\section{DESIGN}

Carers who applied to enter the trial were asked to complete and return a set of questionnaires. Suitable patients and carers were then assessed in a hospital outpatient clinic by a psychiatrist independently of and before group allocation. The diagnosis of dementia was confirmed by investigation if necessary or by checking on previous reports if these were available. Allocation to programmes was decided by sequentially allocating subjects according to the date of their postal application. Those in the "wait list" group were told that there would be a delay until a place in a treatment group was available for them, and they were reassessed six months later, before starting the carers' programme. All subjects were asked to return for interview and reassessment at three, six, 12, and, for those in the wait list group, 18 months. Some participants living in distant rural areas were excused from the three months' follow up but were asked to return self report questionnaires. A sample size of over 30 for each of the three groups was calculated as necessary for an intervention of moderate power (estimate $0 \cdot 6$ ) to produce a relevant effect size (estimate 0.67 ) for $\alpha$ at $0 \cdot 05 .^{12}$

\section{THE DEMENTIA CARERS' PROGRAMME}

This was conducted in the psychiatry unit of a Sydney teaching hospital to which cohorts of up to four patient and carer pairs were admitted at a time. Groups of four were chosen for logistical reasons and to enable the development of small self help groups. The programme was directed mainly at alleviating difficulties associated with being the carer of a person with dementia; the problems were categorised as psychological distress ${ }^{34} ;$ isolation and lack of support ${ }^{313}$; lack of assertiveness and apprehension about new roles ${ }^{78}{ }^{10}$; a poor marital relationship ${ }^{314}$; lack of information about diagnosis, management, prognosis, domiciliary and welfare services, legal and financial matters, and safety and organisation in the home $\mathrm{e}^{15}$; and poor skills at coping. ${ }^{79}$ The techniques used in the programme included didactic education, group therapy, training in management skills, assertiveness training, discussion of "re-roling," extended family therapy sessions, training in techniques for managing problems, basic principles of behaviour modification, and use of activities.

For patients the programme comprised specific sessions in memory retraining, reminiscence therapy, environmental reality orientation, and general ward activities. They had their physical and psychiatric state reviewed, and treatment was offered if indicated. After the programme telephone conference calls linking groups of four carers and the programme coordinator initially took place fortnightly, decreasing over 12 months to four and then six weekly, with two of the final telephone conferences being arranged by the coordinator but held in her absence, the plan being to encourage cohorts of carers to become self supporting.

In the memory retraining group up to four patients with dementia were admitted at a time without their partners and received the patient component of the carers' programme while their carers had 10 days' respite. In the wait list group patients and their carers waited six months before undertaking the carers' programme. Both control groups had telephone conference calls for 12 months after intervention, as described for the carers' programme.

\section{ASSESSMENT}

Patients were assessed on the two scales described by Blessed et al-the orientation information memory concentration scale $^{16}$ (range $0-37 ; 37=$ maximum cognitive functioning) and the dementia scale ${ }^{16}$ (range $=0-27$; higher scores indicate worse function) - and on the mini-mental state examination ${ }^{17}($ range $0-30 ; 30=$ maximum cognitive function, $<17$ indicates important deterioration); the 21 item problem behaviour check lis ${ }^{18}$ (range $0-42 ; 0=$ no problems, $42=$ all problems occurring frequently); the activities of daily living (range $0-6 ; 0=$ completely independent, $6=$ completely dependent); the instrumental activities of daily living ${ }^{10}$ (range $=1-4 ; 1=$ complete independence, higher scores indicate increasing dependence); the 21 item Hamilton rating scale for depression ${ }^{20}$ (range $0-64 ;>16$ indicates important depression); the geriatric depression scale ${ }^{21}$ (range $0-20 ;>10$ indicates possible depression); and the clinical dementia rating scale for dementia ${ }^{22}$ (range $0-3 ; 0=$ healthy, $3=$ severely demented).

\section{CARERS}

Carers completed the general health questionnaire ${ }^{23}$ (range 0-30; those with scores $>4$ probably were significantly depressed) and the Zung depression scale $^{24}$ (range $20-80 ; \geqslant 40$ indicates important depression) and were rated on the Hamilton depression rating scale. They were asked to keep a health diary of all the health care visits made and medications taken by them and the patient over the 12 months of follow up. They were also asked to keep a record of all visits to day centres and any days in residential care. Completion of the diaries was encouraged at the regular telephone conference sessions. Demographic data on all participants were collected and included the position on the Congalton scale for socioeconomic class ${ }^{25}$ (range 1-7; $1=$ highest status occupation, $7=$ lowest ).

\section{STATISTICAL METHODS}

We used repeated measures of analysis of variance, with the multivariate model for comparing outcome; one way analysis of variance to compare groups at entry into the trial; and survival analysis ${ }^{2627}$ to compare how many in each group were not placed in institutions. Four interaction comparisons were planned to determine whether there were differences in the amount of change over six and 12 months between those in the carers' training group and those in the memory retraining group and between those in the carers' training group plus those in the wait list group and those in the memory retraining groups. In addition, we compared the effect of any intervention in the first six months of the carers' programme plus any in the memory retraining programme with the effect of no intervention (the wait list group).

\section{Results}

In all, 101 pairs of patients and carers entered the trial. Three of the 36 pairs in the carers' programme had insufficient follow up data and one of the 32 patients in the memory retraining group changed carers during the follow up period. The data from these 
four pairs were not included in the analyses. Two pairs in the wait list group completed intake and pre-training assessments but elected not to proceed with training. Their data from the initial two assessments were included in the analyses at 0 to 6 months but not subsequently (when theirs were recorded as missing data). All patients and carers who began programmes completed them.

Thus there were 33 pairs in the carers' programme with sufficient follow up data, 31 in the memory retraining programme, and 32 in the wait list group. Of the 96 carers, 44 were men, 89 were spouses, four were siblings, and three were children of the patients; 30 out of the 87 with data belonged to the Alzheimer's Disease and Related Disorders Society. The carers mean (SD) age was $67 \cdot 7(8 \cdot 2)$ years.

Of the 96 patients (50 of whom were men), 70 had probable Alzheimer's disease, 19 had multi-infarct dementia, and seven had other causes of dementia. The average patient was $70 \cdot 2(6 \cdot 5)$ years (range $49-79$ years), had had 10.4 (3.6) years' education, and had mild to moderate dementia (clinical dementia rating scale score $1 \cdot 1(0 \cdot 5)$ ). Patients had a mean duration of dementia of $3.8(3.8)$ years at entry into the trial and there was no significant difference among the groups. Sixteen patients were from social classes I or $\mathrm{II}^{25} ; 52$ were from classes III, IV, or V; 25 were from classes VI or VII; and the data for three patients were missing. There were no significant differences among the three groups for carers or patients in any sociodemographic variable or initial measure of outcome at entry into the trial.

The carers' general psychological morbidity as judged by their scores on the general health questionnaire were lower after the carers' programme (fig 1): differences were significant at 12 months (5.03; $\mathrm{p}<0 \cdot 05)$. There were no significant differences at six months when comparing the carers' programme and wait list groups or the carers' programme plus the memory retraining groups with the wait list group.

The results from the wait list group indicate that merely waiting six months did not influence psychological stress as reflected by general health questionnaire scores. Apart from being slightly more demented on the clinical dementia rating scale (mean 2.7 (1.6) $v$ $2 \cdot 2(1 \cdot 2) ; \mathrm{p}<0.05)$, the patients in the wait list group at the time of their intervention (that is at six months after intake) were not significantly different from the patients in the carers' programme group at their intake (at zero months) with regard to carers' age and general health questionnaire score or patient scores on the minimental state examination, scales of Blessed et al, problem behaviour check list, and geriatric depression scale. We therefore combined the results of follow up

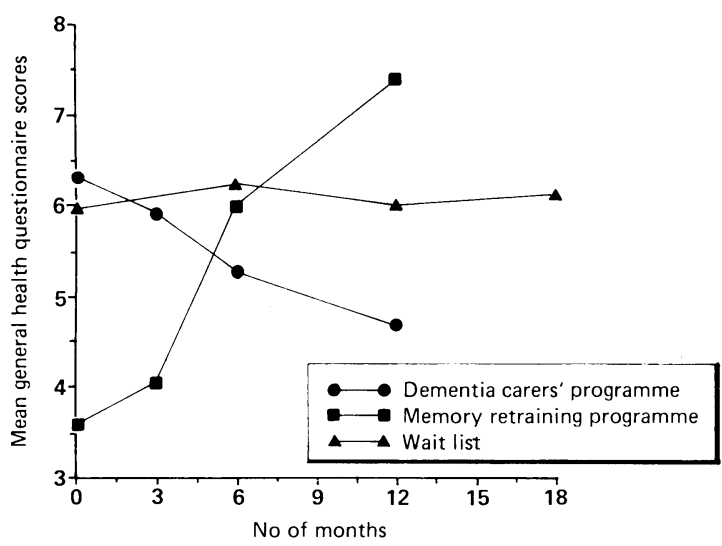

FIG 1-Mean general health questionnaire scores for carers in the three programme groups. Standard deviations of each group at zero, three, six, and 12 months respectively were $6 \cdot 2,5 \cdot 8,6 \cdot 2$, and $5 \cdot 6$ for the dementia carers' programme group; $6.3,7 \cdot 1,8.4$, and 9.4 for the memory retraining group; and $6 \cdot 1$, not available, $6 \cdot 7,6 \cdot 6$, and $7 \cdot 7$ at 18 months for the wait list group

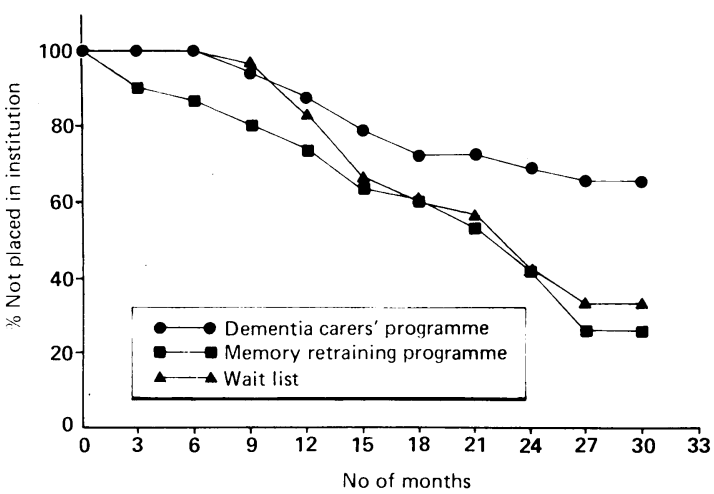

FIG 2-Survival curve showing percentage of patients not placed in an institution over time in the three programme groups

after intervention in the carers' programme group (from 0 to 12 months) with those in the wait list group (from 6 to 18 months) for further comparison with the memory retraining group. Over the six months after training the combined groups of carers receiving the training programme showed a trend of reduced general health questionnaire scores compared with the group of carers not receiving training - that is, those in the memory retraining group $(\mathrm{F}=3 \cdot 01 ; 0 \cdot 05<\mathrm{p}<0 \cdot 10)$. This trend became significant 12 months after training $(\mathrm{F}=6.69 ; \mathrm{p}<0 \cdot 01)$.

Patients initially had mild to moderate dementia, and this became progressively worse over the 12 months of the trial. The rates of decline were roughly linear (table) and equivalent across groups. Patients

Mean (SD) scores in various tests of cognitive function for patients with dementia at allocation to one of three intervention groups (zero months) and at three, six, and 12 months' follow up

\begin{tabular}{|c|c|c|c|}
\hline \multirow[b]{2}{*}{ Test } & \multicolumn{3}{|c|}{ No of months } \\
\hline & $\begin{array}{c}0 \\
(\mathrm{n}=94-6)\end{array}$ & $\begin{array}{c}3 \\
(\mathrm{n}=53-8)\end{array}$ & $\begin{array}{cc}6 & 12 \\
(\mathrm{n}=84-8) & (\mathrm{n}=71-91)\end{array}$ \\
\hline $\begin{array}{l}\text { Clinical dementia rating } \\
\text { scale }\end{array}$ & $1 \cdot 1(0 \cdot 5)$ & Not available & $1.5(0.9) \quad 1.7(0.9)$ \\
\hline $\begin{array}{l}\text { Mini-mental state } \\
\text { examination }\end{array}$ & $17 \cdot 1(6 \cdot 5)$ & $15.9(6.9)$ & $16 \cdot 2(7 \cdot 3) 15 \cdot 2(7 \cdot 6)$ \\
\hline $\begin{array}{l}\text { Orientation information } \\
\text { memory concentration } \\
\text { test }^{\text {tht }}\end{array}$ & $20 \cdot 8$ & $19 \cdot 7(8 \cdot 3)$ & $19 \cdot 4$ \\
\hline Dementia scale" & $7 \cdot 0(2 \cdot 9)$ & $7 \cdot 0(3 \cdot 6)$ & $8 \cdot 2(4 \cdot 3) 10 \cdot 4(5.4)$ \\
\hline $\begin{array}{l}\text { Problem behaviour check } \\
\text { list }\end{array}$ & $6 \cdot 3(5 \cdot 6)$ & $8 \cdot 1(6 \cdot 2)$ & $9 \cdot 8(7 \cdot 2) 11 \cdot 4(8.0)$ \\
\hline $\begin{array}{l}\text { Instrumental activities of } \\
\text { daily living }\end{array}$ & $\begin{array}{l}2 \cdot 3(0 \cdot 8) \\
0 \cdot 3 \cdot 0 \cdot 6)\end{array}$ & $2 \cdot 6(0 \cdot 7)$ & $2.6(0.8) \quad 2.9(0.8)$ \\
\hline Activities of daily living & $0 \cdot 3(0 \cdot 6)$ & $1 \cdot 1(1 \cdot 4)$ & $1.1(1.4) \quad 1.7(1.7)$ \\
\hline
\end{tabular}

were not depressed clinically; fewer than six at any assessment over the 12 months had a Hamilton score $>16$, and their mean Hamilton and geriatric depression scale scores remained low and stable over time.

There was a pronounced divergence in the number of patients being placed in institutions in the different groups at a census undertaken 40 months after the programme began (fig 2). Patients in the dementia carers' programme and the memory retraining programme were followed up for an average of 29 months, and patients in the wait list group were followed up for an average of 19 months. To allow for the different times of entry into the trial survival at home was analysed pragmatically ${ }^{26}$ with the SPSS-X survival program. This analysis allows for patients who die at home and are therefore not eligible to be placed in an institution.

When the three groups were compared over the full period of the study the Lee-Desu statistic ${ }^{27}$ of $6 \cdot 19$ indicated significant differences $(\mathrm{df}=2 ; \mathrm{p}<0.05)$. When the carers' programme and memory retraining programme groups were compared the Lee-Desu statistic of $6.90(\mathrm{df}=1 ; \mathrm{p}=0.01)$ indicated a significantly higher rate of survival at home for patients 
whose supporters had had early training. There had been more deaths at the time of the census in the memory retraining group: 10 patients had died (one at home and nine in institutions) compared with five in the carers' programme group (three at home) ( $\chi^{2}$ with Yates's correction $=1 \cdot 6$ ). In the wait list group two patients had died (one at home) by the time of the census.

\section{Discussion}

The most striking finding was the much lower rate of placement of patients with dementia in institutions, mainly nursing homes, when carers had been through the training programme. It cannot be assumed that avoiding placement in an institution is necessarily desirable, even though supporters usually wish for the patient to be at home for as long as possible. Whether the patient's living at home would lead to more distress for carers compared with his or her placement in an institution, as has been reported, ${ }^{28}$ and greater costs of professional services while the patient is at home compared with those in an institution would have to be weighed up carefully.

The dementia carers' programme did not delay institutionalisation of the patient at the expense of the morbidity of the carer. On the contrary, it reduced psychological morbidity as measured by the general health questionnaire. This difference became more pronounced at 12 months' follow up, suggesting a long term effect for the programme. (No differences were found in ratings of depression in carers among groups or over time. Low initial depression scores [mean (SD) Zung depression score $34.8(8 \cdot 9) ; n=94$ and Hamilton depression score $6.7(5 \cdot 2) ; \mathrm{n}=88$ ], however, may have precluded any such benefits from the carers' programme.)

The increased rate of retaining the patient at home was not likely to be at the expense of increased usage of the health service. Over the first 12 months after training there were no differences between the patients or carers in the carers' programme and the memory retraining programme in how often they attended consultations or took drugs.

It could be argued that the carers' programme was not necessarily beneficial and that the important results emerged as a result of the memory retraining group's deterioration over time; perhaps carers in the memory retraining group were disappointed by their patient's lack of improvement. It may have been that after the 10 days' respite afforded by the memory retraining programme carers became more keenly aware of the extent of their burden. Another explanation, which we favour, is that the general health questionnaire scores of the memory retraining group were approaching their expected level of morbidity. Thus in an earlier survey of members of the Alzheimer's Disease and Related Disorders Society we found that the mean general health questionnaire score was $7 \cdot 3,{ }^{3}$ which is similar to that described by Gilleard. ${ }^{4}$

We concede the weakness of setting $\alpha$ at 0.05 , given the number of comparisons. To correct for the possible increase in the rate of type 1 errors associated with the four planned comparisons a conservative procedure would be to set $\alpha$ at $0 \cdot 05 / 4=0 \cdot 0125$. As many variables may affect carers' psychological morbidity, ${ }^{5}$ our power analysis estimates were optimistic and numbers of subjects too small. When the number of subjects was increased by combining both groups of carers who had received training the difference in general health questionnaire scores between them and untrained carers over 12 months was significant at the $p<0.01$ level.

Regarding the patients, it was clear that the programme could not affect the relentless progression of the dementias, most of which were of the Alzheimer's type. Whatever test was used to monitor patient state, be it of cognitive function, problem behaviours, day to day functioning, or overall severity, there was a consistent linear decline, which was similar in all three groups. Our impression, however, was that after training there was an observable improvement in the morale of patients.

The much less striking results from the wait list group are puzzling, especially given the comparable severity of the disease by all of the measures except one at the time of intervention. Perhaps carers were disappointed at not receiving immediate attention. Alternatively, it may be that the timing of such an intervention is important-earlier is better. This is supported by our impressions that carers seemed to derive more benefit and were able to use the strategies in coping in a preventive manner when they received earlier training.

We cannot yet comment on which aspects of the dementia carers' programme are effective. This would require several further studies examining its different components. One of us (HB) interviewed all of the carers after 12 months' follow up and asked which components of the training had been most helpful. No element of the programme emerged consistently as the most helpful, and virtually all elements were considered by at least some carers to be particularly beneficial. We cannot comment on which carers and which patients are most likely to benefit from such a programme: additional analyses will be required to determine further the question of specificity.

Patients in the carers' programme group were at home at least 5.2 months longer than patients in the memory retraining programme group. (This calculation is based on the conservative assumption that all patients were placed in institutions the day after the census.) This may not, however, represent any financial savings as the cost of care in an institution must be weighed against the costs of the programme and of professional support while the patient is at home. As good domiciliary care is no cheaper than good institutional care the basis for further argument must rest therefore on the quality of life for both patient and carer.

We conclude that an intensive intervention programme for carers of patients with dementia early in the course of the patient's illness has the potential to delay institutionalising the patient and reduce the psychological morbidity of the carer without increasing the use of health services.

We thank Carol Mahy, Eva Palmer, Karin Peters, Dianne Griffin, Dusan Hadzi-Pavlovic, Gordon Parker, Tony Jorm, Scott Henderson, Joy Chaffey, Linda Hayward, Gordon Pettigrew, the participating patients and carers, the Alzheimer's Disease and Related Disorders Society, and the referring doctors for their help, support, and encouragement. Prince Henry Hospital supported the admission of patients and carers. The study was supported by a grant from the Commonwealth Department of Health.

1 Anderson R. The unremitting burden on carers. Br.Med f 1987;294:73.

2 Gilhooly $M$. The impact of care-giving on care-givers: factors associated with he psychological well-being of people supporting a dementing relative in the community. Br F Med Psychol 1984;57:35-4

3 Brodaty $\mathrm{H}$, Hadzi-Pavlovic $\mathrm{D}$. The psychosocial effects on carers of living with dementia. Aust $N Z \mathcal{F}$ Psychiatry (in press)

4 Gilleard CJ. Influence of emotional distress among supporters on the outcome of psychogeriatric day care. Br $\mathcal{F}$ Psychiatry 1987;150:219-23.

5 Morris RG, Morris LW, Britton PG. Factors affecting the emotional wellbeing of the caregivers of dementia sufferers. Br 7 Psychiatry 1988;153:147-56.

6 Levine NB, Dastoor DP, Gendron CF. Coping with dementia: a pilot study. J Am Geriatr Soc 1983;31:12-8.

Levine NB, Gendron CE. Dastoor DP, et al. Supporter endurance training. a manual for trainers. Clinical Gerontolgist 1984;2:15-23.

8 Zarit $\mathrm{SH}$ Zari JM. Families understess: inerven dementia patients. Psychotherapy: Theory, Research and Practice 1982;19: dementia 
9 Gendron CE, Poitras LR, Engels ML, et al. Skills training with supporters of the demented. F A $m$ Geriatr Soc 1986;34:875-80.

10 Kahan J, Kemp B, Staples FR, Brummer-Smith K. Decreasing the burden in families caring for a relative with a dementing illness. $\mathcal{f}$ Am Geriatr Soc 1985;33:664-9.

11 Katz S, Akpom CA. A measure of primary sociobiological functions. $\operatorname{Int} \mathcal{f}$ Health Serv 1976;6:493-507.

12 Bird KD, Hall W. Statistical power in psychiatric research. Aust $N Z \mathcal{Z}$ Psychiatry 1986;20:189-200.

13 Zarit S, Reever K, Bach-Peterson J. Relatives of the impaired elderly: 2arit S, Reever K, Bach-Peterson J. Relatives of the impared
correlates of feelings of burden. Geromtologist 1980;20:649-54.

14 Fitting $M$, Rabins $P$, Lucas $M J$, Eastham J. Caregivers for dementia patients: a comparison of husbands and wives. Gerontologist 1986;26:248-52

15 Brodaty H, Griffin D, Hadzi-Pavlovic D. A survey of dementia carers: how doctors communicate with dementia patients and their carers; the problem behaviours of dementia; and factors associated with institutionalisation. Aust $N Z \mathcal{F}$ Psychiatry (in press).

16 Blessed G, Tomlinson BE, Roth M. The association between quantitative measures of dementia and of senile change in the cerebral grey matter of elderly subjects. Br f Psychiatry 1968:114:797-811.

17 Folstein MF, Folstein SE, McHugh PR. "Mini-mental state": a practical method for grading the cognitive state of patients for the clinician. Fournal of Psychological Resources 1975;12:189-98.

18 Gilleard CJ, Boyd WD, Watt G. Problems in caring for the elderly mentally infirm at home. Arch Gerontol Geriatr 1982;1:151-8.

19 Lawton MP, Brodie EM. Assessment of older people: self-maintaining and instrumental activities of daily living. Gerontologist 1969;9:179-86.

0 Hamilton M. A rating scale for depression. I Neurol Neurosurg Psychiatry 1960;23:56-62.

21 Yesavage JA, Brink TL, Rose TL, Adey $M$. The geratric depression rating scale: comparison with other self-report and psychiatric rating scales. In: Crook T, Ferris S, Bartus R, eds. Assessment in geriatric psychopharmacology. New Canaan, Connecticut: $M$ Dowley, 1983.

22 Hughes CP, Berg L, Danzieger WL, Coben LA, Martin RL. A new clinical scale for the staging of dementia. Br f Psychiatry 1982;140:566-72.

23 Goldberg D. The detection of psychiatric illness by questionnaire. New York: Oxford University Press, 1972.

24 Zung WWK. Depression in the normal aged. Psychosomatics 1967;8:287-92. 25 Congalton AA. Status ranking list of occupations in Australia. Appendix B to status and prestige in Australia. Melbourne: FW Cheshire, 1969.

26 Schwartz D, Lellouch J. Explanatory and pragmatic attitudes in therapeutic

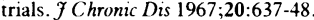

27 Lee E, Desu M. A computer program for comparing $\mathrm{K}$ samples with rightcensored data. Computer Programs in Biomedicine 1972;2:315-21.

28 Wells Y, Jorm AF. Evaluation of a special nursing home unit for dementia sufferers: a randomised controlled comparison with community care. Aust $N$ Zf Psychiatry 1987;21:524-31.

(Accepted 12 September 1989)

The total creatine kinase activity was appreciably

Acute right heart strain after crushing injury at Hillsborough football ground

\section{K S Channer, D L Edbrooke, M Moores, P McHugh, S Michael}

Intensive Care Unit, Royal Hallamshire Hospital, Sheffield S10 2JF

K S Channer, MD, consultant cardiologist

D L Edbrooke, FCANAES, consultant anaesthetist

M Moores, FCANAES, senior registrar in anaesthetics

P McHugh, FCANAES, senior registrar in anaesthetics

S Michael, FCANAES, lecturer in anaesthetics

Correspondence to: Dr Channer. cardiac function in these six young men.
Ninety five people died from crushing injuries and asphyxiation at Hillsborough football ground in April 1989. Eighty one others were admitted to hospitals in Sheffield. Of the 18 patients who required artificial ventilation, five were transferred to this hospital for treatment and computed tomography of the head, and one further patient was admitted to this hospital. In all six men (aged 15-23) the brain scan was normal, though they had been asphyxiated by crushing and cerebral hypoxia had occurred. Five had epileptiform convulsions; one had bilateral pneumothoraces and one negative results on laparotomy. None had bone injuries. We report the effect of asphyxiation on

\section{Patients and methods}

All six patients were ventilated and examined on admission. Electrocardiograms were recorded daily and echocardiograms on day one and day three or four. Blood samples were taken within the first 24 hours and on days two and three after injury to measure creatine kinase activity, including the myocardial isoenzyme and lactate dehydrogenase isoenzyme 1 activities.

In two patients the initial electrocardiogram showed a nodal rhythm and in one left axis deviation and left bundle branch block. The other four were in sinus rhythm, and by day two all were in and remained in sinus rhythm. The electrical axis was rightward $\left(+90^{\circ}\right)$ in four patients initially, and one patient developed right axis deviation by day two.

There was a dominant $R$ wave in $V 1$ with an $R s R$ pattern in two patients and this appeared by day three in three further patients. $T$ wave inversion developed in leads V1 to V5 in three patients and resolved within two weeks.

Initial echocardiograms showed dilated and impaired right ventricles in four patients. Left ventricular function was reduced in three due to septal hypokinesia. The mean ejection fraction was 0.66 (range $0 \cdot 46-0 \cdot 85$ ), becoming normal in all (mean $0 \cdot 83$, range $0 \cdot 7-0 \cdot 9$ ). Two patients had small transient pericardial effusions, and three had persistent abnormalities of right ventricular function. raised, being compatible with muscle damage, but the cardiac isoenzyme fraction was not raised and the cardiospecific lactate dehydrogenase fraction was slightly raised in all patients (maximum $34 \%$ of total lactate dehydrogenase activity, normal $<25 \%$ ).

\section{Comment}

In all six patients the apparent injury was similarthoracic compression causing hypoxia, loss of consciousness, and convulsions. Unusually, there was no
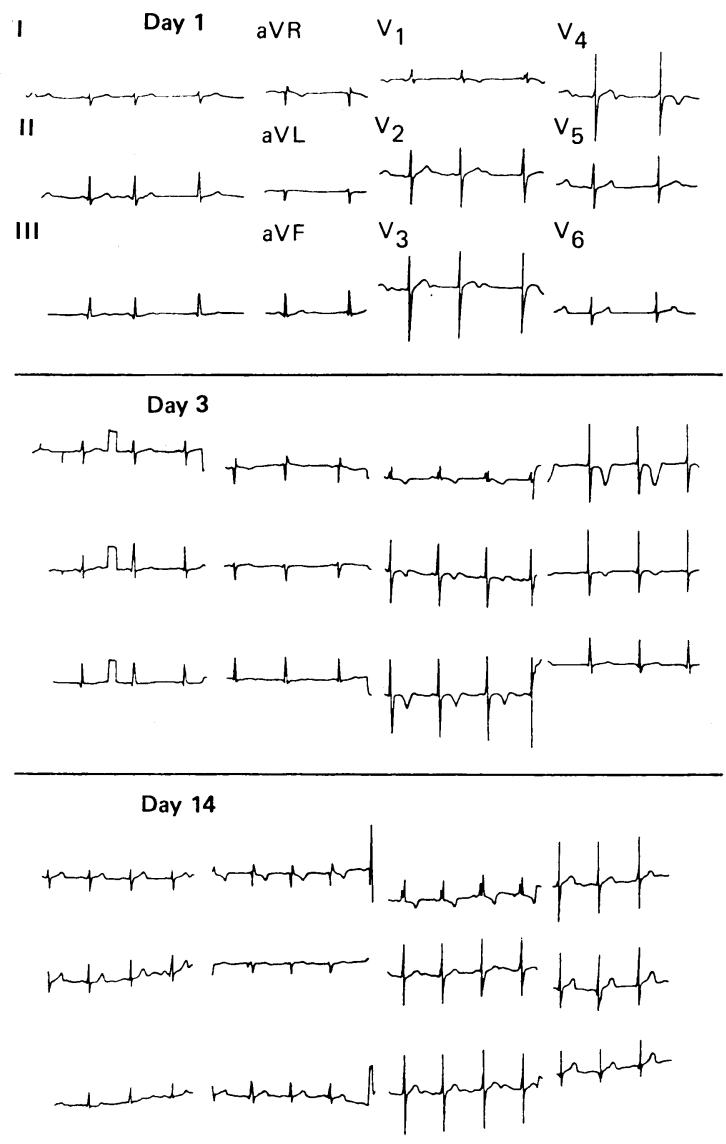

Serial electrocardiographic recordings in one patient. On day one there was right axis deviation, sinus rhythm with blocked atrial premature beats and sinus arrest and nodal escape beats, partial right bundle branch block, and non-specific ST and T wave changes in V3 and V4. On day three axis is $>+90^{\circ}$, and there is complete right bundle branch block. There is marked T wave inversion in VI to V5. On day 14 the axis remains at $+90^{\circ}$, and there is partial right bundle branch block and the $T$ wave changes have resolved 